\title{
Aedes aegypti na rede: uma análise das estratégias de combate ao mosquito pelos sites do Ministério da Saúde
}

\section{Aedes aegypti in the network: an analysis of combat strategies against the mosquito in the sites of Brazil's National Health Department}

\author{
Kristianne Maia MOREIRA ${ }^{1}$ \\ Cláudio Márcio MAGALHÃES ${ }^{2}$ \\ Cláudia Chaves FONSECA ${ }^{3}$ \\ Victor Alves de Almeida SOARES ${ }^{4}$
}

\begin{abstract}
Resumo
O objetivo deste estudo foi fazer uma análise de quatro páginas da internet do Ministério da Saúde no que se refere ao combate ao mosquito Aedes aegypti, de dezembro de 2018 a março de 2019. Como base teórica, o debate do uso das tecnologias da informação e comunicação e artefatos tecnológicas para a construção de sítios na internet que levem em conta eixos importantes como participação e tecnologia. Foi realizada uma abordagem qualitativa, baseada na observação e registros estruturados e sistematizados, comparando os conteúdos com as referências na literatura que preconizam uma comunicação social tecnológica, analisado criticamente o conjunto de páginas que enfoca o combate ao mosquito. Como resultado, as análises demonstraram antagonismo em relação as suas próprias mensagens de participação comunitária e de tecnologia, haja vista que pouco oferecem para instrumentalização desse trabalho conjunto e espaços de interação. Dado que o objetivo era explorar as eventuais deficiências na comunicação dos sites, o artigo lista propostas para o seu aprimoramento ao combate ao Aedes aegypti.
\end{abstract}

Palavras-chave: Aedes; Internet; Participação Social; Comunicação Social; Ciência, Tecnologia e Sociedade.

\footnotetext{
${ }^{1}$ Mestre em Gestão Social, Educação e Desenvolvimento Local pelo centro Universitário UNA (2012). Email: kristiannemoreira@bol.com.br.

${ }^{2}$ Doutor em Educação e Mestre em Comunicação Social pela UFMG. Jornalista e Professor do Mestrado em Gestão Social, Educação e Desenvolvimento Local e do Instituto de Comunicação e Artes nos cursos de Jornalismo Multimídia, Cinema e Video e Publicidade e Propaganda. E-mail: claudiomagalhaes@uol.com.br.

${ }^{3}$ Doutora em Educação pela PUC Minas (2017). Mestre em Comunicação (2001) e bacharel em Jornalismo (1987) pela Universidade Federal de Minas Gerais (UFMG). É membro do grupo de pesquisa Mídia e Narrativas, do Mestrado em Comunicação da Pontifícia Universidade Católica de Minas Gerais. E-mail: claufon@gmail.com.

${ }^{4}$ Graduado em Publicidade e Propaganda, Webdesigner. E-mail: victorsoaresa.alves@gmail.com.
} 


\section{Abstract}

This paper aims to analising the Brazil's National Health Department internet sites. It focus on their information about how to fight Aedes aegypti mosquito and offering propositions to improve the mosquito combat. We have studied the literature on how to use technological tools on sites building that took on account important topics such as participation and social technology. Then we analised and made a discussion discussed Brazil's National Health Department sites that dealed with mosquito combat. The sites' analyses observed conflict on information about community participation and social technology. There were scarce information on how to help and put in reality the partnership work and interation setting. The paper offers a list of propositions to improve sites about Aedes aegypt fighting.

Keywords: Aedes; Internet; Social Participation; Social Communication; Science, Technology and Society.

\section{Introdução}

O mosquito Aedes aegypti transformou-se. Muito conhecido pela população em geral por transmitir a dengue, a espécie também transmite outras doenças igualmente graves como a febre amarela urbana, a Chikungunya e a Zika. O Ministério da Saúde segue à frente do exército contra o inseto e clama que a vitória só acontecerá se houver uma mobilização social. $\mathrm{Na}$ era da informação e da proliferação das redes sociais, o armamento pode ser sofisticado. Assim, as interfaces virtuais do Ministério deveriam ser a vanguarda e a referência para os combatentes, dado que é o órgão do Executivo que administra as políticas públicas. Em papel especial estariam seus canais na internet, suas possibilidades e potencialidades, mesmo que ainda constituam um conhecimento em contínuo processo de construção. Afinal, o direito à saúde, previsto na Constituição Federal de 1988, atualmente somente se efetiva quando o direito à Comunicação também acontece.

O trabalho de porta a porta continua sendo o mais válido e importante, dadas as características da população mais vulnerável ao mosquito. No entanto, as novas tecnologias, e a sua rápida expansão pelos smartphones presentes em todas as camadas da população, podem ser inseridas neste contexto contribuindo para a disseminação de informações importantes no que tange à doença e à forma de combatê-la.

Este artigo propõe-se a analisar se isso acontece nesse momento em que a informação e o engajamento comprovam-se como principais instrumentos de combate 


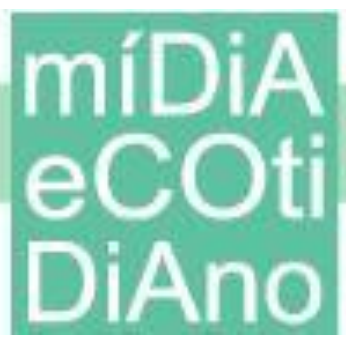

epidemiológico. E sugere adaptações à tecnologia de combate contra o Aedes aegypti por esses mesmos mecanismos já existentes no Ministério da Saúde. O campo da comunicação e saúde $(\mathrm{CeS})$ vem crescendo em uma sociedade midiatizada como a brasileira, conforme esclarecem Emerich et al (2016):

O campo da comunicação e saúde $(\mathrm{CeS})$ articula-se em diversas vertentes, pautado no entendimento de que o direito à comunicação é indissociável do direito à saúde, já que o primeiro potencializa a participação e autonomia dos sujeitos, confere visibilidade às necessidades e demandas de saúde e ao Sistema Único de Saúde (SUS), contribuindo (ou não) para a efetivação do segundo direito. As informações desse campo integram conhecimentos que analisam quais doenças e necessidades de saúde têm sido abordadas pela mídia, quais as principais demandas de saúde de um território e quais fatores estão inseridos na dinâmica de construção e veiculação das notícias de saúde (EMERICH et al., 2016).

A doença original que alçou o Aedes aegypti ao patamar de vilão nacional, a dengue, é uma das doenças virais mais importantes do mundo. Acomete milhões de pessoas, particularmente nos países de clima tropical, onde a temperatura e a umidade facilitam a proliferação do vetor Aedes aegypti. Várias tentativas têm sido implantadas pelos governos para minimizar e/ou controlar a expansão dessa doença. Entre as estratégias usadas nas campanhas de saúde pública está a tentativa de conscientização e mobilização da comunidade por meio do uso de novas tecnologias. A internet tem sido usada com frequência como importante instrumento de apoio à promoção da saúde da sociedade. No entanto, mesmo sabendo que o uso de sites na internet pode contribuir sobremaneira com os propósitos das campanhas contra a dengue, esse recurso não tem sido usado de maneira eficiente, especificamente no caso das páginas do Ministério da Saúde, como se verá a seguir nos relatos das observações e análises que se fizeram ao longo da investigação.

A inadequação da comunicação social do Ministério da Saúde já havia sido detectada por Vasconcelos, Oliveira-Costa e Mendonça (2016). Em um trabalho ainda mais amplo que a presente pesquisa, os pesquisadores analisarem 14 campanhas e concluíram que há um grande desequilíbrio entre as tarefas de prevenção de doenças e a da promoção da saúde. Apenas três das campanhas tinham a promoção como objetivo. 


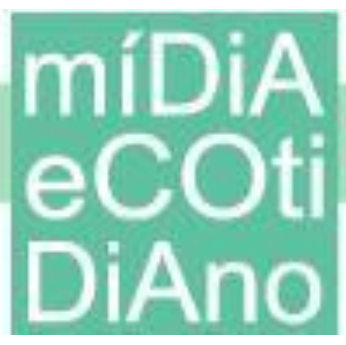

Ora, tendo o combate ao mosquito uma necessidade de intersetorialidade e sendo ela um dos pilares da promoção da saúde, haja vista que se espera a articulação dos diversos agentes, lugares e culturas, o foco na prevenção distorce as peculiaridades de cada local e público-alvo. A esse respeito, afirmou Simeone (2008, p.1): "novas preocupações não se resumem à pontualidade das ocorrências, mas se estendem por um longo curso de eventos problemáticos a exigir a junção de constante vigilância, em curto prazo, com aspectos culturais e educacionais para mudança de hábitos, a longo prazo".

Tanto naquela pesquisa quanto nesta não se questiona a necessidade de prevenção, ao contrário, mas que seja dada atenção proporcional aos problemas do país e à promoção à saúde. O que se verá é que os sites do Ministério da Saúde pesquisados carecem de linguagem, conteúdo e recursos adequados para que se possa atingir o usuário no sentido de informá-lo, realizar uma mudança de comportamento e promover a saúde. Um dos caminhos para resolver essa situação é adequar-se às demandas do utilizador, construindo um site com e para a comunidade, de maneira que este seja não apenas uma tecnologia disponível, mas uma tecnologia que promova o desenvolvimento da sociedade, mesmo cientes de que há uma população ainda com dificuldades do uso de tecnologias de informação como instrumento de cidadania. No entanto, o Ministério da Saúde não pode se furtar de avançar nesses seus próprios instrumentos, também ciente que a capacitação tecnológica da população se torna cada vez mais veloz com a disseminação dos smartphones e outros aparatos técnicos. Dar uma pequena contribuição a esse contexto é a proposta deste trabalho.

\section{Um mosquito real num mundo virtual}

Há algum tempo não era comum conseguir informações detalhadas sobre doenças, tratamentos e/ou medicamentos a que a população era exposta, a não ser por consulta direta a algum profissional de saúde. O crescimento da internet reverteu essa situação e vive-se uma era virtual onde é possível encontrar na rede todo o tipo de informação.

Assim, em se tratando especificamente de uma doença como a dengue, as informações estão a um clique dos usuários da internet. Mas, certamente, é preciso que 
sejam informações de fácil acesso, precisas e claras, para que haja chances de consolidar o conhecimento e contribuir para uma maior promoção da saúde da população em geral.

\section{Dengue}

Em todo o Brasil, são realizados diversos tipos de campanha com o objetivo de informar a população a respeito da dengue e de seus meios de controle. A maioria dessas campanhas dá ênfase ao controle do mosquito vetor visto que, enquanto não há uma vacina eficaz que proteja a população contra o dengue-vírus, o mais provável é que a dengue continue a ser um problema grave nos anos que virão, pois a imunização contra a doença ainda enfrenta alguns sérios entraves. Dessa forma, a maior arma de controle da doença é a erradicação do mosquito Aedes aegypti por meio de programas de controle eficientes, da vigilância epidemiológica ativa e atuante, da melhoria do diagnóstico laboratorial e, principalmente, da educação para a saúde.

Sabendo-se que, no momento, a medida mais eficaz de controle da doença é a erradicação dos focos de reprodução do mosquito transmissor, faz-se necessário fortalecer a consciência individual e coletiva, sensibilizando o público em geral quanto à importância da colaboração de todos na tentativa de erradicar o agente transmissor. Para tanto, pode-se e deve-se utilizar todas as formas de divulgação de informações sobre a doença, de maneira a conscientizar a todos - sociedade e governo - da importância da participação nesse processo.

Em 1996, o Ministério da Saúde (MS) criou o Plano de Erradicação do Aedes aegypti - PEAa ${ }^{5}$ (BRASIL, 2002). Durante a aplicação desse programa, percebeu-se o

\footnotetext{
${ }^{5}$ O Plano de Erradicação de Aedes aegypti teve como principal objetivo criar e ministrar novos métodos de erradicação do mosquito, além de atentar-se, principalmente, aos casos de dengue hemorrágica que, grande parte das vezes, levava à morte. Sustentava ações descentralizadas de controle do vetor para estados e municípios alterando o modelo então vigente de gestão verticalizada e centralizada. Embora sem alcançar seus principais objetivos, o PEAa mostrou-se importante, pois propôs a necessidade premente de atuação multissetorial no combate à dengue. Os resultados obtidos por esse programa confirmaram a inviabilidade de uma política de erradicação do vetor a curto prazo e, a partir daí, o MS faz uma reavaliação de todo o programa incorporando a ele novas e importantes facetas. como a participação comunitária e a mobilização social. Com isso, em 2002, é instituído o Programa Nacional de Controle da Dengue (PNCD), que incorpora as experiências nacionais e internacionais enfatizando a
} 


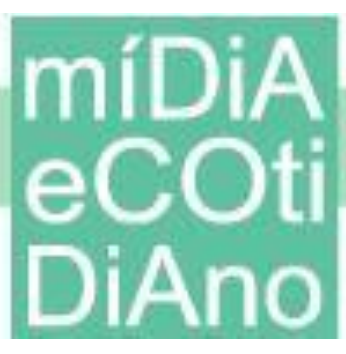

quão é importante e necessário ter-se um modelo descentralizado de combate à doença, com a participação da população e de todos os níveis e setores de governo e a sociedade civil. E que essas campanhas deveriam abranger as mais diversas formas de comunicação de massa, desde distribuição de folhetos informativos até propagandas maciças em televisão, rádio e internet.

Até o final de 2018, o site oficial do MS (portalms.saude.gov.br) era utilizado como material de apoio educativo e informativo de informação e educação para o combate ao mosquito da dengue, o Aedes aegypti. No entanto, em sua página principal, não há nada que redirecione imediatamente a informações sobre Dengue, Febre Amarela Urbana, Zika ou Chikungunya: informações a respeito dessas doenças são somente encontradas ao se pesquisar outros tópicos no site. É certo que a parcela mais significativa da população tem dificuldades no acesso e/ou no manuseio desses instrumentos na rede de computadores, mas a informação digital tem entrada para formadores de opinião e multiplicadores, como agentes de saúde e educadores. Porém, de qualquer forma, com ou sem sites eficientes, o real crescimento do número de casos da doença leva a crer que, mesmo com a utilização desses artefatos, as campanhas de controle da dengue não têm sido eficazes no cumprimento dos seus objetivos.

\section{Políticas públicas de combate ao Aedes aegypti}

Para que uma política pública seja eficaz, é preciso que esteja integrada ao seu público-alvo: a sociedade para quem ela é dirigida. No âmbito do controle da dengue, todos os anos, são lançados programas de controle nos vários níveis de governo, desde o municipal até o nível federal. Entretanto, até bem pouco tempo atrás, esses programas apresentavam-se de forma setorial e desarticulada, como no já citado Programa de Erradicação do Aedes aegypti (PEAa).

necessidade de programas de controles permanentes (uma vez que não há evidencias técnicas possíveis de erradicação do mosquito a curto prazo), elaboração de campanhas de mobilização e informação de pessoas (responsabilidade social), fortalecimento da vigilância epidemiológica e entomológica e integração de programas de saúde pública, como o Programa de saúde da Família (PSF) por exemplo, às ações de controle do mosquito, entre outros. 
Dessa forma, foi necessário que fossem desenvolvidos trabalhos intersetoriais, descentralizados, fruto de uma rede de ações em que houvesse o envolvimento de todos os setores da sociedade em rede e não apenas dos profissionais de saúde - mas também dos governos em todos os seus níveis e setores (vigilância epidemiológica e entomológica, centros de saúde, agentes de saúde, entre outros), das escolas (alunos, professores grupos de pais), que devem se comprometer a elaborar e implementar ações eficazes de controle do vetor em áreas que podem oferecer condições para a proliferação dos mosquitos.

Em relação à descentralização, entende-se aqui que as ações em saúde pública devem ser distribuídas entre as três esferas de governo: federal, estadual e municipal. No entanto, essa distribuição não deve ser feita de forma descoordenada, mas em um panorama que abarque o que se chama de intersetorialidade que, de acordo com Junqueira, Inojosa e Komatsu (1997, p.24), é entendida como "a articulação de saberes e experiências no planejamento, realização e avaliação de ações, com o objetivo de alcançar resultados integrados em situações complexas, visando um efeito sinérgico no desenvolvimento social".

É, também, o que se entende por atuar em rede. Segundo Scherer-Warren (1999), as redes caracterizam-se pela busca de articulações mais horizontalizadas, evitando o centralismo e a burocratização organizacional. No entanto, atuar em rede gera um aumento de responsabilidade de cada um dos setores envolvidos e, por outro lado, faz gerar o sentido de cooperação e participação na busca de respostas para os diversos problemas que assolam as sociedades.

Em relação ao Aedes aegypti, a palavra rede é extremamente usada e referese à mobilização da sociedade por meio de políticas públicas de ações práticas que objetivam controlar o avanço da doença. Já a participação, peça chave para a erradicação (ou diminuição) do número de casos de doenças relacionadas ao mosquito, relaciona-se ao envolvimento da sociedade nas ações contra o inseto.

Trata-se, então, principalmente da participação comunitária nas políticas públicas, em que toda a comunidade é entendida como parte do problema e, portanto, tem poder decisório sobre ele. Alguns autores, entre eles Paim (2009 apud CIRINO; TUZZO, 2015) propõem uma distinção entre sistemas de saúde e sistemas de serviços de saúde. 


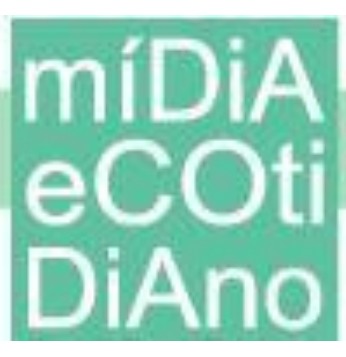

Os primeiros são todas as instituições sociais que podem assumir o papel de promoção da saúde, tais como a escola, as igrejas e a mídia. Os segundos são os serviços organizados, a exemplo de hospitais, laboratórios, clínicas etc. É por meio de uma atuação integrada, envolvendo as múltiplas redes sociais, que tem o alcance de mobilizar tanto os sistemas de saúde quanto os sistemas de serviços de saúde, que se viabiliza uma eficiente ação coletiva para controlar a proliferação dos mosquitos Aedes aegypti.

Diferentemente do PEAa, as políticas públicas mais recentes tentam abarcar os conceitos de rede e intersetorialidade. Obviamente, isto significa um avanço, se comparadas às políticas anteriores, mas muitos outros problemas ainda estão por resolver.

\section{Saúde e novas tecnologias}

É notório o impacto da internet sobre as mais diversas áreas da atividade humana em tão pouco tempo desde sua popularização a partir dos anos 1990 (BRIGGS, BURKE, 2004; LESSIG, 2005; CASTELLS, 2011; GLEICK, 2013). Especificamente em relação à saúde, é difícil precisar a dimensão do impacto que a internet gera a respeito desse assunto, para o bem ou para o mal. As informações digitais referentes à saúde são tantas e tão variadas que, para designar esse grande espectro, foi criado a expressão $e$ health ou e-saúde (com o e referindo-se a "eletrônico"). Mas, em particular, pode-se perceber muito claramente o quanto a rede tem sido usada em prol das campanhas de saúde coletiva, como, por exemplo, nas campanhas contra o Aedes aegypti, assunto do qual se trata esta pesquisa.

Vê-se, então, evidente que a utilização da internet, nesse caso, especificamente o site oficial do Ministério da Saúde do Brasil, como apoio às ações de combate ao Aedes aegypti, é primordial e tem grande potencial para traduzir-se em material de apoio efetivo às ações. Tal medida deve-se justificar pelo acesso crescente das pessoas à rede, embora, efetivamente, não se possa afirmar que este seja um instrumento eficiente e eficaz, pois não se sabe como e de que maneira essas informações chegam às pessoas. E o mais importante: se elas se apropriam delas (o que gera, de fato, as ações em torno de alguma questão). 
O que caracteriza a atual revolução tecnológica não é a centralidade de conhecimentos e informação, mas a aplicação desses conhecimentos e dessa informação para a geração de conhecimentos e de dispositivos de processamento/ comunicação da informação, em um ciclo de realimentação cumulativo entre a inovação e seu uso (CASTELLS, 2011, p. 69).

Devido ao aumento do uso da internet, principalmente pelos mais jovens, as campanhas virtuais contra o Aedes aegypti, nos sites do Ministério da Saúde e das secretarias estaduais e municipais, deveriam ser um dos principais instrumentos. No entanto, como já dito, não se sabe se os conhecimentos e informações fornecidos por eles estão realmente sendo úteis ao que se propõem.

Lévy (1992) ressalta que as novas tecnologias digitais são um campo vasto e conflituoso. De fato, em se tratando de saúde, inúmeras questões devem ser levadas em conta ao se criarem políticas públicas e programas que prevejam o uso da internet. $\mathrm{O}$ surgimento dessas novas tecnologias permite a busca, o processamento e a interação dos serviços de saúde pela população. Segundo o IBGE (2016), em 2014, mais da metade da população brasileira possuía acesso à internet. Dados da Pesquisa Nacional por Amostras de Domicilio Contínua (PNAD Contínua) mostram que, em 2017 a utilização da internet nos domicílios permanentes do país era de 74,9\% frente a 69,3\% em 2016. Houve, também, crescimento significativo da utilização da internet em domicílios da área rural; $75,0 \%$ em 2016 e 80,1\% em 2017. Esse mesmo tipo de evolução foi observado em todas as grandes regiões do país. Dessa forma, é possível perceber que existem meios de alcançar e levar informações sobre a saúde, especificamente sobre a dengue, chicungunya e o zika, de forma rápida e interativa para a maioria da população brasileira. Certo que pode ainda haver problemas na usabilidade das pessoas, mas também mostra deficiência nesses canais de comunicação em se mostrarem relevantes, contribuindo com a falta de interesse do usuário.

Em relação ao combate ao Aedes aegypti, pode-se afirmar que, embora haja iniciativas de controle e erradicação do mosquito, com o uso da internet, como o próprio site do Ministério da Saúde e a inserção do assunto em plataformas de redes sociais de grande alcance, como o Facebook (rede social mais utilizada no mundo por usuários ativos), existem diversos complicadores referentes ao acesso da sociedade a essas 


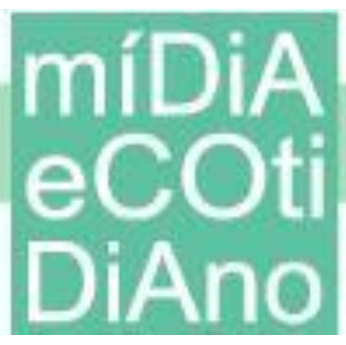

informações. Há que se considerar, também, a variabilidade das características educacionais da população das diversas regiões do Brasil onde se concentram os maiores níveis de casos das doenças; a formação dos profissionais de saúde envolvidos diretamente no combate e campanhas de prevenção e controle; a qualidade e a maneira como é disposta a informação na rede; entre tantas outras peculiaridades que podem influir de maneira direta no combate ao mosquito.

Cada uma dessas variáveis comportaria investigações específicas, e este trabalho tem como foco a análise, crítica e contribuição em apenas um dos seus aspectos, o que não diminui a sua importância e nem releva as demais. Mas está em consonância com a própria área de saúde, cada vez mais empenhada em se aproximar das ciências da comunicação, em especial as envolvidas em novas tecnologias, com a saúde (FUNDAÇÃO OSWALDO CRUZ, 2017; PESSONI, 2015), inclusive na formação profissional (MORAES; VASCONCELLOS, 2006).

\section{Educação em saúde e internet no combate ao Aedes aegypti}

A educação em saúde historicamente tem o objetivo de atuar na prevenção de doenças e promover a saúde da população. Tem um amplo espectro que inclui desde técnicas para adesão ao tratamento como também técnicas orientadas para a prevenção de enfermidades. Em 1994, o Governo Federal institui o "Programa de Saúde da Família" com a proposta de mudar o modelo de atenção básica à saúde no país. Anteriormente, o enfoque educativo baseado somente na prevenção de doenças começa a ser repensado e ações voltadas para a humanização dos serviços de saúde passam a ser observadas. Essa "humanização" dos serviços de saúde nada mais é do que considerar o indivíduo como agente transformador da própria saúde, munido de crenças, valores e conhecimentos prévios, enfim, de uma história de vida.

Embora ainda predominem algumas práticas educacionais intervencionistas em relação ao controle de endemias e epidemias, não se pode negar que elas vêm acompanhadas da ideia de participação. Contribuíram para essas mudanças a infinidade de saberes difundidos pela e na comunidade. Nesse sentido, qualquer proposta de site que queira auxiliar no combate ao Aedes aegypti deve levar em consideração a participação 


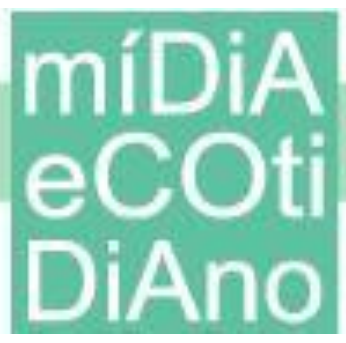

das comunidades, o compartilhamento de conhecimentos, a educação formal e informal e as interações sociais entre os agentes das campanhas.

Em um programa de controle do mosquito, há que se levar em conta quais valores, significados, sentidos e informações circulam sobre o Aedes aegypti na sociedade. Torna-se necessário entender como a saúde e as doenças afetam a experiência de vida cotidiana das pessoas, como as populações afetadas percebem o ambiente e como o processo de adoecimento afetam essas pessoas.

De forma sintética, desenvolver um processo educativo na sociedade civil organizada ou em vias de organização implica: a) procurar conhecer a realidade, compreender seus problemas e buscar soluções; b) potencializar sujeitos e valores emergentes que caminham para a transformação e superação dos problemas; c) eleger, em cada momento, os problemas, os projetos, as formas de atuação e as estratégias prioritárias (SCHERER-WARREN, 1999, p. 61).

Faz-se necessário, ainda, avaliar como a cultura organiza e modifica a experiência social e a educação nos aspectos relativos ao combate ao Aedes aegypti. Assim, nas atividades de educação ou mobilização social em saúde, devem-se observar valores e crenças que permeiam os modos das populações perceberem e identificarem seus próprios problemas. O conhecimento deve começar a ser apreendido a partir de uma perspectiva global para que depois possam ser inseridos os conhecimentos parciais e locais. É necessário, portanto, articular competências e saberes para a aquisição e incorporação de habilidades e conhecimentos e, também, estimular atitudes pessoais de comprometimento com um projeto comum de mudança da realidade.

Dentro do processo educativo, para que haja aprendizagem, é preciso que o que está sendo ensinado tenha significância. Isso permite que educação em saúde propicie mudanças reais na qualidade de vida da comunidade. Isso significa uma interação entre o que se está aprendendo e o que já se sabe. Assim, o conhecimento antigo torna-se mais elaborado a partir do momento em que um novo conhecimento tenha significado para o indivíduo. Nesse sentido, as inovações tecnológicas representam um marco para o processo educacional. Elas romperam totalmente a fronteira imposta pelo modelo do ensino escrito e oral e a chamada educação on-line torna-se cada vez mais presente e nos mais variados níveis de ensino. 


\section{míDiA \\ ecc DiAno}

\section{Metodologia}

Para este estudo foi utilizada a abordagem qualitativa, mais adequada para se alcançar os objetivos propostos que, em suma, eram o de observar, analisar e propor melhorias aos sites do Ministério da Saúde no que tange ao combate ao Aedes aegypti. Após estudos a partir de leituras bibliográficas e documental, que resultaram na referencia teórica até aqui, foi feito um estudo investigativo e interpretativo de quatro dos sites do Ministério da Saúde, que tinham estrita referência ao mosquito, de dezembro de 2018 a março de 2019.

São eles: Portal principal do Ministério da Saúde ${ }^{6}$; o Saúde de A a Z, um glossário de busca ${ }^{7}$; o específico de combate ao Aedes aegypti ${ }^{8}$; e o específico sobre a dengue ${ }^{9}$. Para isso, foi utilizado um modelo de técnica de observação estruturada ou sistemática, que consiste em coletar e registrar eventos previamente, além de analisá-los a partir de critérios estabelecidos em consonância com os objetivos deste trabalho, tais como informação de fácil acesso, possibilidades de interatividade e participação, atrair o interesse sobre a temática e convidar à ação.

\section{Resultados e Discussão}

A partir dos dados obtidos durante a pesquisa bibliográfica (SANTOS, 2010; LANDER, 2013; DVIR; GAFNI, 2018), considerou-se que um site bem construído deve conter funcionalidades informativas e interativas, além de componentes de usabilidade facilitada, chamada à atenção, orientação, de navegação e de comunicação bem estruturados. Deve-se considerar também identidade, curiosidade, rapidez de acesso, níveis de interatividade, informação, atividades, espaço de partilha. Em resumo, um bom site deve atrair a atenção, despertar interesse, criar desenho e chamar à ação (LANDER, 2013).

De modo geral, o portal do MS possui uma estrutura semelhante aos portais de notícias mais visitados do país, como o Globo.com, UOL e MSN. Os conteúdos são

\footnotetext{
${ }^{6}$ Disponível em: <portalms.saude.gov.br> e <saude.gov.br>.

${ }^{7}$ Disponível em: <portalms.saude.gov.br/saude-de-a-z>.

${ }^{8}$ Disponível em: <portalms.saude.gov.br/combate-ao-aedes>.

${ }^{9}$ Disponível em: <portalms.saude.gov.br/dengue>.
} 
distribuídos em formatos de chamadas e menus, dando destaques para notícias que estejam relacionadas ao Ministério e a saúde pública de modo geral, focados mais em conteúdo de informações de relatos. Na página principal do site do Ministério da Saúde na ocasião das observações, pôde-se observar que não há nenhuma informação de fácil acesso, tratando especificamente sobre o mosquito Aedes (Figura 1), como uma informação visível destacada em primeiro plano. Com o alto número de picadas de escorpiões notificadas neste verão 2018/2019, a página principal do site traz como informação primordial os cuidados necessários frente à acidentes com este animal embora aconteça também no verão, o aumento de casos de doenças transmitidas pela picada do mosquito Aedes.

Figura 1 - Portal do Ministério da Saúde

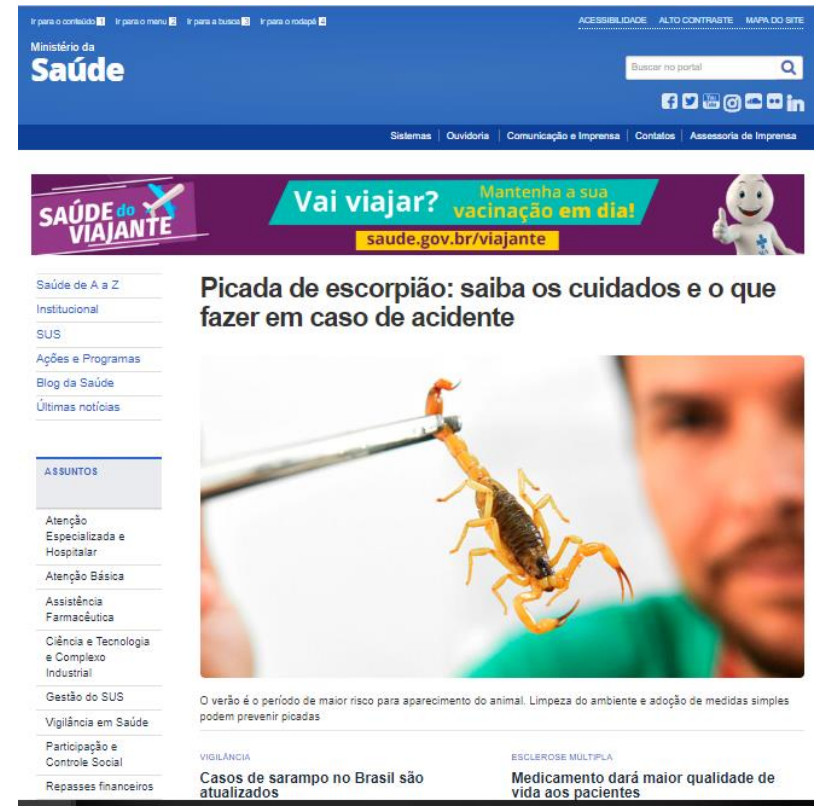

Fonte: Ministério da Saúde.

Ao se navegar pelo site em busca de informações sobre o Aedes será necessário clicar no tópico "Saúde de A a Z" que redirecionará à página portalms.saude.gov.br/saude-de-a-z. Nesta página, por meio de tópicos distribuídos por ordem alfabética, encontram-se informações específicas sobre dengue, chikungunya e zika (Figura 2). 
Figura 2 - Saúde de A a Z

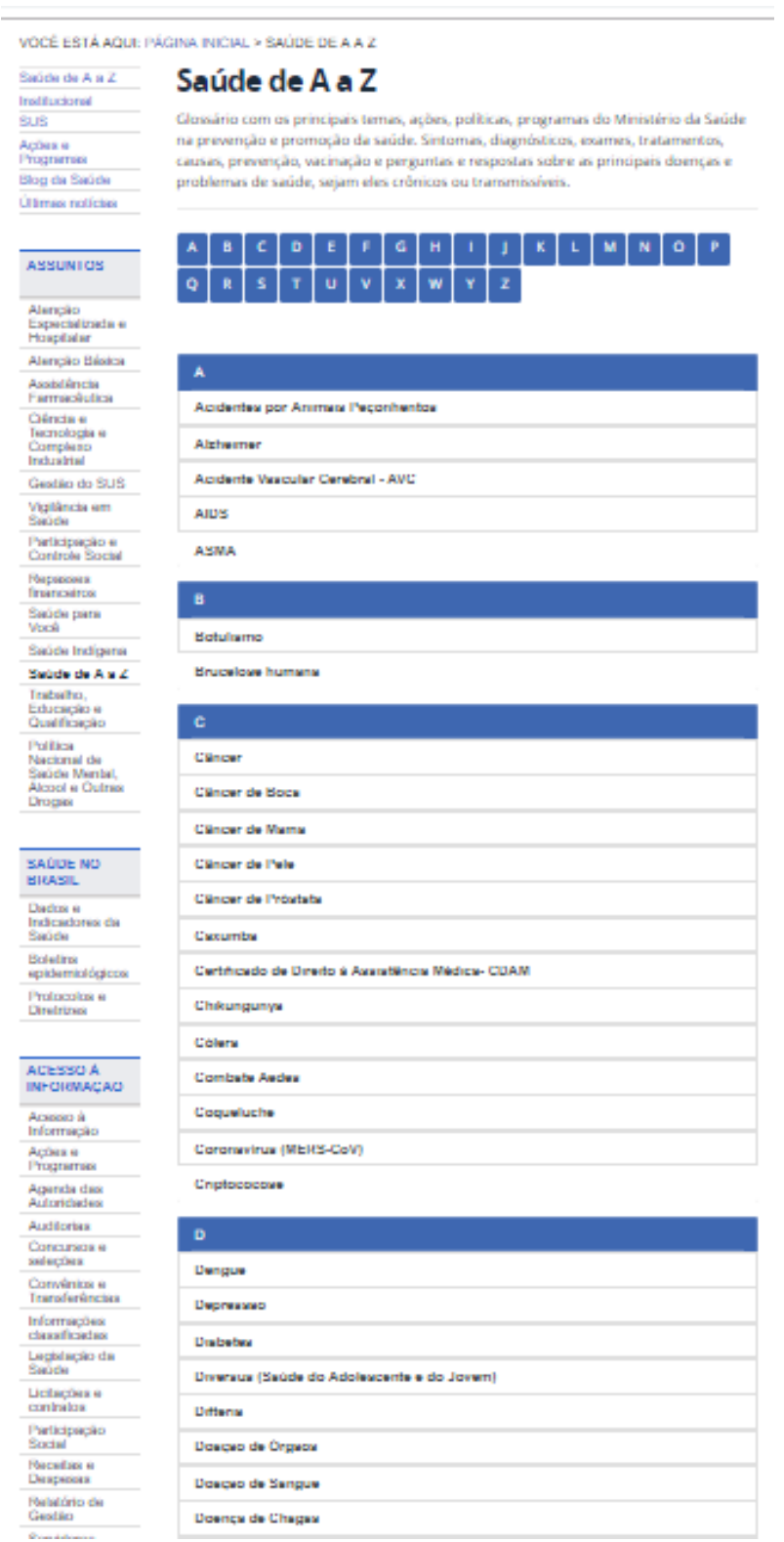

Fonte: Ministério da Saúde.

De modo geral, o site tem estrutura pouco dinâmica que exige do internauta uma grande necessidade de cliques e análise da página, como se vê nas imagens dentro do site, com tópicos para cada uma das doenças transmitidas pelo Aedes. O usuário é forçado a clicar em vários links para saber mais informações referentes a cada item julgado como importante. Essa prática dificulta o processo de leitura dinâmica e universal sobre o tema, o que pode resultar em um grande índice de rejeição da página. Uma 


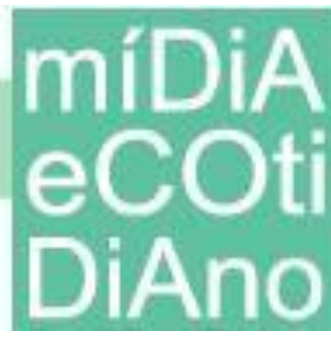

rejeição que pode levar o usuário a buscar informações em outras fontes mais claras e rápidas.

Atualmente, o acesso à internet é feito em sua maioria pelo celular $(98,7 \%)$, como aponta o relatório da Pesquisa Nacional por Amostra de Domicílios Contínua (AGÊNCIA IBGE, 2017), ultrapassando os 52,3\% do acesso via computador desktop, microcomputador e tablet. Em 2014, a maior proporção do uso foi registrada no Nordeste, onde mais de $92 \%$ dos domicílios tinham o celular como meio de acesso à internet (IBGE, 2014). Vale lembrar que a região Nordeste foi a mais afetada pela incidência do vírus Zika, causando um aumento dos casos de microcefalia em recém-nascidos da região. Diante desses dados, é importante ressaltar que, embora venha crescendo de forma exponencial o acesso à internet - e isto poderia contribuir para um maior entendimento sobre a dengue - o Ministério da Saúde alerta que houve um crescimento de 264,1\% dos casos da doença no Brasil nas primeiras 11 semanas de 2019 em relação a 2018. Os números indicam que em 2018 os casos de dengue estavam na casa de 62,9 mil infectados pelo vírus e em 2019 este número subiu para 229.064 (até 16 de março). A região Sudeste é a que apresenta o maior número de casos: $149.804,65,4 \%{ }^{10}$.

A pesquisa do IBGE expõe a realidade dinâmica da disseminação da informação e a necessidade de uma maior interação entre o conteúdo e os usuários. A competitividade da atenção do usuário de um celular é intensa diante a diversidade de aplicativos disponíveis para uso, ainda mais pela predominância que os aplicativos de interação social têm demonstrado. Dessa forma, quando um internauta chega a uma página, é necessário que pelo menos as principais informações estejam disponíveis na página de acesso. Essa estrutura não é observada na página do Ministério da Saúde, na qual o usuário necessita procurar e clicar em mais links para saber informações simples.

Para mudar essa estrutura, sugere-se a criação de uma landing page (SANTOS, 2010; LANDER, 2013; DVIR; GAFNI, 2018) para o portal e para suas principais páginas, como a que aborda cada uma das doenças transmitidas pelo mosquito. As “páginas de conversão", do termo em inglês Landing Pages (SANTOS, 2010), têm como

\footnotetext{
10 Disponível em: <www.portalms.saude.gov.br/noticias/agencia-saude/45314-cresce-em-264-o-numerode-casos-de-dengue-no-pais>. Acesso em: 31 mar. 2019.
} 
objetivo agregar novas páginas ao site original para produzir uma conversão desejada ao propósito do negócio. A criação dessas páginas tem o objetivo de fornecer ao usuário de um conteúdo uma espécie de recompensa pelo acesso, como o download de um e-book, e transformá-lo em um usuário frequente do site. Para o Ministério da Saúde, a criação de landing pages poderia favorecer uma maior dinamização do acesso e do uso do site por novos usuários.

As páginas de conversão tendem também a apresentar mais conteúdo no mesmo local, não forçando o usuário a realizar cliques que redirecionam para mais e mais páginas. Quando todo o conteúdo está no mesmo lugar, torna-se mais fácil manter o usuário consumindo-o até o fim. Na página inicial do Ministério da Saúde de A a Z, ao se clicar nos links sobre as doenças transmitidas pelo Aedes aegypti, como a dengue, por exemplo, o usuário é direcionado para uma página (Figura 3) com outros diversos links com tópicos e informações sobre as doenças. Entre estes links há um que se lê 'Acesse nossa página especializada em combate ao Aedes'. Ao se acessar essa página (figura 4) não se encontra nenhuma nova informação ou informações mais detalhadas sobre o tema, mas apenas alguns links direcionam o usuário a vídeos de propagandas veiculadas na televisão ou áudios de propagandas de rádio. As duas páginas são pobres em qualidade visual do conteúdo, não utilizam nenhum recurso visual que não os textos para explicar as doenças, os sintomas, as causas e todas as informações consideradas importantes para o usuário. As informações sobre chikungunya e zika, de maneira geral, também seguem o mesmo padrão dentro do portal do Ministério da Saúde. 
Figura 3 - Saúde de A a Z - Dengue
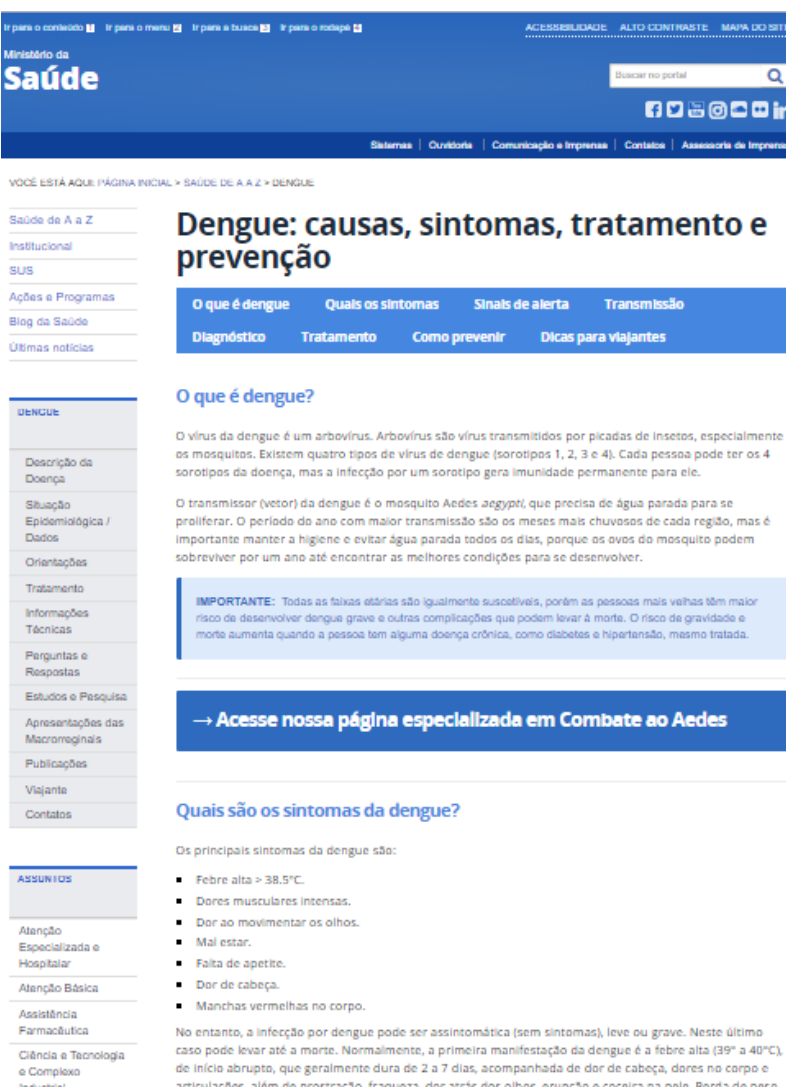

Fonte: Ministério da Saúde. 
Figura 4 - Saúde de A a Z - Combate ao Aedes

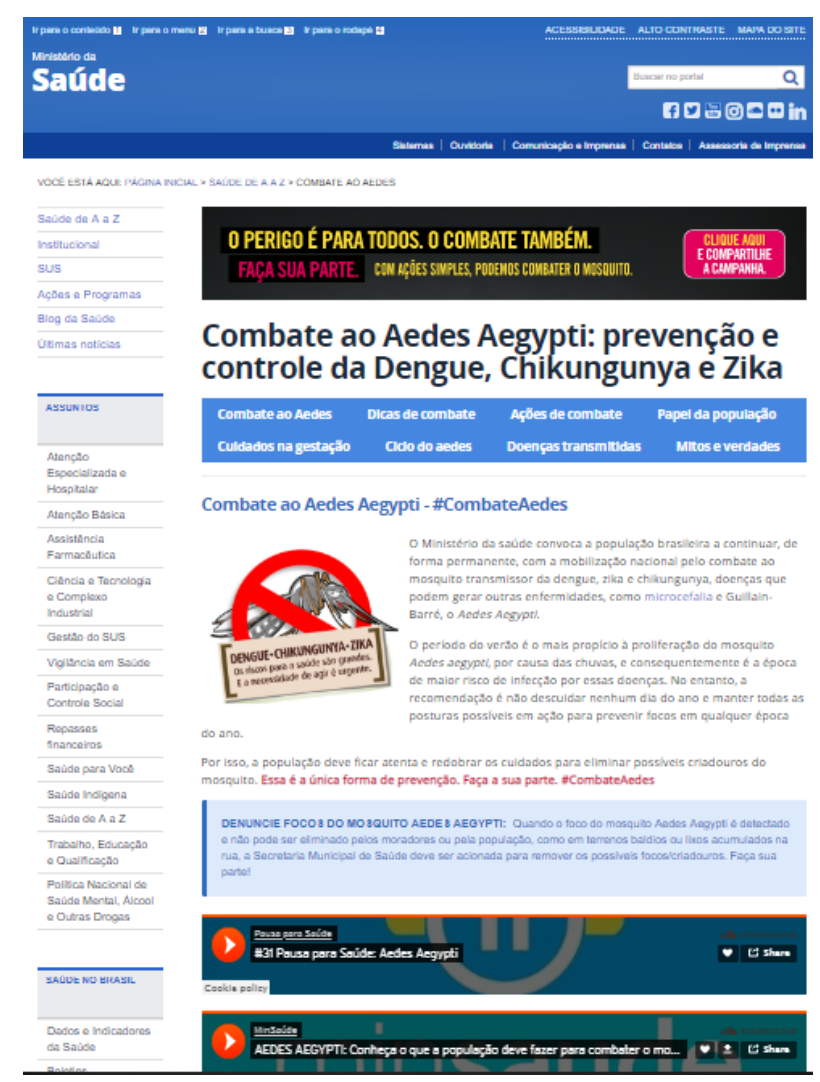

Fonte: Ministério da Saúde.

Atualmente, os principais sites e blogs da internet, de diversos segmentos, como notícias, esporte e entretenimento, estão buscando usar novas formas de gerar conteúdo (SILVA; PETRUCELLI, 2018), como infográficos e vídeos, pois o comportamento do usuário tende a escolher conteúdos dinâmicos e que possam gerar interação de alguma forma. Esse comportamento mostra a importância que o usuário dá a conteúdos que imergem em determinado tema. Dessa forma, é interessante para o Ministério da Saúde aliar-se a essas estratégias tecnológicas, criando canais em redes sociais, a fim de desenvolver e compartilhar vídeos dinâmicos que venham a informar e entreter os usuários. Tal iniciativa reforçaria a estratégia, tão requisitada à população, de combate compartilhado ao mosquito.

Utilizar dos novos meios de comunicação e adotar as estratégias mais novas do mundo digital, é uma importante forma de aproximar a sociedade da magnitude dos problemas causados pelo Aedes aegypti e construir uma consciência de responsabilidade 
na população sobre o combate ao mosquito. Uma alternativa de saída para isso é transformar o site Combate ao Aedes e, até mesmo, o Portal da Saúde (site principal do Ministério da Saúde) em meios nos quais a população possa consumir informações que venham a incrementar algo de novo em suas vidas, bem como adquirir conteúdos relevantes e usuais, assim como participar ativamente com suas próprias contribuições.

Para o Portal da Saúde, a criação de um blog que inclua informações e dicas do mundo da saúde para a sociedade, com conteúdo transformador, diferente do que atualmente é visto, apenas informações oficiais sobre pesquisas e eventos do MS. Como exemplo, o site BuzzFeed, uma fonte de inspiração para os principais blogs e sites do país, pois adota uma nova linguagem jornalística que explora o conteúdo e a experiência do usuário, mesclando humor e conteúdo informativo de maneira séria e inovadora (ADNEWS, 2013). O site busca a geração de conteúdo viral e dinâmico e, para as marcas estarem ali, elas precisam se adequar ao estilo do portal. Tomando como exemplo o estilo do BuzzFeed, uma publicação que envolveria a discussão sobre o mosquito da dengue e o comportamento da sociedade poderia adotar o seguinte título: "17 vezes em que você ajudou a ter mais mosquito em casa". A publicação apoia-se em uma lista informativa e interativa que mostra ao usuário ações comuns do dia a dia em que ele não está atento para proliferação do mosquito e em cada tópico uma solução poderia ser apontada.

Nesse modelo de conteúdo, em que o usuário pode se sentir parte do material e encontra soluções básicas para seus problemas cotidianos, é possível criar uma relação de proximidade. Usando-se dessas táticas, o portal do Ministério da Saúde poderia encontrar um meio de se tornar referência para a sociedade encontrar conteúdo relevante concernente às questões de saúde pública. Seria importante abusar de dispositivos que tornem o cidadão protagonista do site e, consequentemente, difusor das ideias ali abordadas, principalmente os cuidados com o combate ao mosquito Aedes aegypti.

Essas propostas, entretanto, não tratarão de assuntos demasiadamente técnicos relacionados à construção de um site, visto que o objetivo é propor um site mais atrativo e funcional para os usuários que tenha como foco o combate ao Aedes aegypti.

Assim, sugere-se que:

- a linguagem utilizada seja clara e, sempre que possível, sem palavras e expressões consideradas "difíceis" (obviamente, no que se refere às 
doenças, vez ou outra, será necessário o uso de terminologias científicas ou mais complexas). Para que isso não se torne um problema para o usuário, o site deverá conter logo na frente do texto a explicação do termo científico que for utilizado;

- mecanismos de participação mais efetiva das comunidades e dos grupos de interesse, como agentes de saúde, líderes comunitários e mesmo o cidadão comum, que possam interagir, dialogar e integrar os sites, atualizando e tornando-os dinâmicos e factuais;

- as informações busquem sempre viés "aproximador" entre o internauta e as doenças, de maneira que o usuário entenda que mosquito convive com ele na sua casa e que ele é o principal agente de combate;

- o contexto social, no qual o indivíduo se encontra, seja levado em consideração. Na prática, dentro do site, sugere-se que seja inserida uma tecnologia que adapte o site à região ou estado ao qual o usuário pertence, mudando, por exemplo, o tipo de linguagem no que se refere à abordagem das informações;

- a disposição de links dê acesso fácil a outras páginas acerca do assunto, caso o internauta queira obter um maior aprofundamento sobre a doença;

- a existência de um destaque, em tempo real, informe sobre a situação em que o país se encontra frente ao mosquito e quais são as medidas que estão sendo adotadas;

- a inserção, no conteúdo do site, de informações relacionadas diretamente ao professor traga sugestões de atividades dentro e fora da sala de aula, literatura sobre a dengue voltada diretamente para o educador, entre outros;

- a oferta de cursos on-line, disponibilizando certificados ao final e divulgando os nomes daqueles que melhor se saíram no curso, constitua uma fonte de motivação para profissionais envolvidos no controle da doença; 
- a criação de jogos online e sugestões de como realizar brincadeiras dentro da sala de aula, encenações teatrais, participação em feiras sejam opções de atividades para serem realizadas na escola;

- o uso de recursos permita que o usuário "interaja" com o portal, como fóruns de discussão. Seria também interessante que o usuário possa se cadastrar no site e receber informações atualizadas a respeito das doenças transmitidas pelo mosquito, lembretes de como ele deve agir no seu ambiente para ajudar a minimizar a ocorrência da doença, entre outras possibilidades;

- Cadastro e inscrições na página, para receber notificações, alertas de endemias, epidemias ou mesmo campanhas locais na região onde o usuário reside, convites e estímulos para visita em outros perfis do ministério.

\section{Conclusão}

Não é possível conceber o desenvolvimento de um país sem se pensar seriamente nas questões de saúde pública. A dengue, especificamente, é uma doença grave e, mesmo com todos os esforços empreendidos, continua provocando mortes ano após ano. A recente descoberta da ligação do Aedes aegypti com a Zika já causa certo pânico mundial pelas suas consequências graves. Mas, as estratégias de combate ao mosquito encontram sérios percalços, como a complexidade das populações, a desorganização do ambiente urbano, a miséria. Em virtude de todas essas características, aliadas a outras mais, o combate ao Aedes aegypti requer grande esforço da população e, nesse sentido, a palavra "desenvolvimento" significa colocar as pessoas em contato direto com o problema, mobilizando-as e incentivando-as a atuarem diretamente nas ações de combate à doença.

No entanto, a introdução de inovações nas práticas de saúde, em geral, e no controle do Aedes aegypti, em particular, é um grande desafio, pois inclui a modificação de fatores sociais e culturais. Mas, vale ressaltar que não se trata de reduzir as soluções técnicas, mas rever os princípios que modelam as práticas, no sentido de torná-las mais 
eficientes. Assim, sabendo-se do grande poder de penetração que a internet representa na atualidade, faz-se necessário fazer dela uma aliada.

Além de subsidiar a tomada de decisões dos gestores sobre quais ações de controle, prevenção e vigilância devem ser priorizadas. A constatação de elevados coeficientes de incidência em praticamente todos os municípios [na Bahia], além de verificar que o vírus da dengue não respeita espaços sociais e diferenças econômicas, fortalece a necessidade de implementar ações de combate vetorial em caráter abrangente (MARTINS et al., 2015, p. 71-72).

O uso da rede, portanto, pode ter um alto poder educativo. Segundo Rousiley Maia (2002), as novas tecnologias de comunicação e informação, incluindo, nesse caso, a internet, parecem oferecer vantagens diversas sobre os meios de comunicação tradicionais, proporcionando um ideal para a comunicação democrática, uma vez que seus dispositivos interativos e multifuncionais oferecem novas possibilidades para a participação descentralizada. Como afirma a autora, essas novas tecnologias permitem colocar diferentes parceiros de interlocução em contato, através de ações recíprocas e vínculos virtuais variados, criando um potencial de interação inédito. Trata-se não apenas da conectividade isolada do usuário da rede, mas sim do potencial de conexão coletiva, aproximando os cidadãos dos assuntos que os envolvem. O site do MS e os outros sites ligados a essa instituição devem se prestar eficazmente a esse papel.

Para finalizar, é importante reconhecer que a internet, seu conteúdo, suas possibilidades e potencialidades constituem um conhecimento ainda em processo de construção. Dessa forma, pode-se afirmar: esse trabalho estará, inegavelmente, em permanente construção. Mesmo porque, como se comprova pela dinamicidade do mosquito, o Aedes aegypti mostra que ele mesmo está se modificando e adaptando e, portanto, seu combate deve ser igualmente flexível e moderno.

\section{Referências}

ADNEWS. 7 razões que mostram: BuzzFeed é a morte e a salvação do Jornalismo. 2013. Disponível em: <https://bit.ly/2DqSUi9>. Acesso em: 9 nov. 2017.

AGÊNCIA IBGE. PNAD TIC: em 2014, pela primeira vez, celulares superaram microcomputadores no acesso domiciliar à Internet. 2014. Disponível em: <https://bit.ly/37O3s9a>. Acesso em: 9 nov. 2017. 
BRASIL. Ministério da Saúde do Brasil. Diretrizes nacionais para prevenção e controle de epidemias de Dengue. Ministério da Saúde, Secretaria de Vigilância em Saúde. Departamento de Vigilância Epidemiológica, Brasília-DF, 2009.

BRASIL. Ministério da Saúde. Programa Nacional de Controle da Dengue. Brasília, DF: Ministério da Saúde, Fundação Nacional da Saúde, 2002. Disponível em: <https://bit.ly/34y26gw>. Acesso em: 9 nov. 2017.

BRIGGS, A.; BURKE, P. Uma história social da mídia: De Gutemberg à Internet. Rio de Janeiro: Jorge Zahar, 2004.

CASTELLS, M. A sociedade em rede - a era da informação: economia, sociedade e cultura. 5. ed. São Paulo: Paz e Terra, 2011.

CIRINO, J. A.; TUZZO, S. Comunicação e saúde: a mídia como agente social de saúde. In: CONGRESSO DE CIÊNCIAS DA COMUNICAÇÃO NA REGIÃO CENTRO-OESTE INTERCOM, 17., 2015, Campo Grande. Anais... São Paulo: Intercom, 2015. Disponível em: <https://bit.ly/2Y1y8z9>. Acesso em: 10 nov. 2017.

DVIR, N.; GAFNI, R. When Less Is More: Empirical Study of the Relation Between Consumer Behavior and Information Provision on Commercial Landing Pages. Informing Science: The International Journal of an Emerging Transdiscipline, [s.1.], v. 21, p.019-039, 2018. Informing Science Institute. Disponível em: <https://bit.ly/34AJzk0>. Acesso em: 5 fev. 2019.

EMERICH, T. et al. Necessidades de saúde e direito à comunicação em tempos de midiatização. Reciis - Rev Eletron Comum Inf Inov Saúde, v.10 n. 4. out-dez. 2016.

FUNDAÇÃO OSWALDO CRUZ. Política de comunicação da Fiocruz. Rio de Janeiro: Fiocruz, 2017.

GLEICK, J. A informação: uma história, uma teoria, uma enxurrada. São Paulo: Companhia das Letras, 2013.

HENRIQUES, M. S. Comunicação e mobilização em saúde: da propaganda à interlocução. Rev Diversa, Belo Horizonte, v. 7, n. 16, 2008.

IBGE. Acesso à internet e à televisão e posse de telefone móvel celular para uso pessoal 2014. Coordenação de Trabalho e Rendimento. Rio de Janeiro, 2016. Disponível em: <https://bit.ly/2L12FHW>. Acesso em: 9 nov. 2017.

JUNQUEIRA, L. A. P.; INOJOSA, R. M.; KOMATSU, S. Descentralização e intersetorialidade na gestão pública municipal no Brasil: a experiência de Fortaleza. In: CONCURSO DE ENSAYOS DEL CLAD EL TRÁNSITO DE LA CULTURA BUROCRÁTICA AL MODELO DE LA GERENCIA PÚBLICA, 11., 1997, Caracas. Anais. Caracas, 1997. p. 53 - 124. Disponível em: <https://bit.ly/2OWWxBK>. Acesso em: 9 nov. 2017.

LANDER, J. How to design an effective website landing page. Inventors' Digest, v. 30, n. 2, p. 40-42, fev. 2013.

LESSIG, L. Cultura livre: como a grande mídia usa a tecnologia e a lei para bloquear a cultura e controlar a criatividade. São Paulo: Trama, 2005.

LÉVY, P. As tecnologias da inteligência: o futuro do pensamento na era da informática. Lisboa: Instituto Piaget, 1992. 
MAIA, R. C. M. Redes Cívicas e Internet. In: EISENBERG, J.; CEPIK, M. Internet e política: teoria e prática da democracia eletrônica. Belo Horizonte: UFMG, 2002. p. 46-72.

MARTINS, M. M. F. et al. Análise dos aspectos epidemiológicos da dengue na microrregião de saúde de Salvador, Bahia, no período de 2007 a 2014. Revista Espaço para a Saúde, Londrina, v. 16, n. 4, p. 64-73, 2015. Disponível em: 〈https://bit.ly/2Ot4i3f〉. Acesso em: 7 nov. 2017.

MORAES, I. H. S., VASCONCELLOS, M. M. Gestão da informação e comunicação em saúde: desenho e implementação de uma proposta de ensino-aprendizagem. In: LEAL, M. C.;

FREITAS, C. M. (Orgs.) Cenários possíveis: experiências e desafios do mestrado profissional na saúde coletiva [online]. Rio de Janeiro: FIOCRUZ, 2006.

PESSONI, A. (Org.). Comunicação, saúde e pluralidade: novos olhares e abordagens em pauta. São Caetano do Sul: USCS; 2015.

SANTOS, E. O que são páginas de conversão e por que elas são importantes para seu negócio. Resultados Digitais. 2010. Disponível em: <https://bit.ly/34x6xbI>. Acesso em: 9 nov. 2017.

SCHERER-WARREN, I. Cidadania sem fronteiras: ações coletivas na era da globalização. São Paulo: Hucitec, 1999.

SILVA, G. A.; PETRUCELLI, E. E. Princípios de UX design no desenvolvimento de websites. Revista Interface Tecnológica, v. 15, n. 2, p. 28-38, 29 dez. 2018.

VASCONCELOS, W. R. M.; OLIVEIRA-COSTA, M. S.; MENDONÇA, A. V. Promoção ou prevenção? Análise das estratégias de comunicação do Ministério da Saúde no Brasil de 2006 a 2013. RECIIS - Revista Eletrônica de Comunicação, Informação \& Inovação em Saúde, v.10, n.4, Abr-Jun 2016. Disponível em: 〈https://bit.ly/2Ou6nvZ〉. Acesso em: 9 nov. 2017. 